\title{
OPTIMIZATION OF A RANDOM FOREST CLASSIFIER FOR BURNED AREA DETECTION IN CHILE USING SENTINEL-2 DATA
}

\author{
E. Roteta ${ }^{1, *}$, P. Oliva ${ }^{2}$ \\ ${ }^{1}$ Deparment of Geography, Prehistory and Archaeology, University of the Basque Country, Spain - ekhi.roteta@ehu.eus \\ ${ }^{2}$ Hémera Centro de Observación de la Tierra, Universidad Mayor, Chile - patricia.oliva@umayor.cl
}

KEY WORDS: fires, South America, Sentinel-2, GEE, machine learning, satellite imagery

\begin{abstract}
:
Due to the high variability of biomes throughout the country, the classification of burned areas is a challenge. We calibrated a random forest classifier to account for all this variability and ensure an accurate classification of burned areas. The classifier was optimized in three steps, generating a version of the burned area product in each step. According to the visual assessment, the final version of the BA product is more accurate than the perimeters created by the Chilean National Forest Corporation, which overestimate large burned areas because it does not consider the inner unburned areas and, it omits some small burned areas. The total burned surface from January to March 2017 was $5,000 \mathrm{~km}^{2}$ in Chile, $20 \%$ of it belonging to a single burned area in the Maule Region, and with $91 \%$ of the total burned surface distributed in 6 adjacent regions of Central Chile.
\end{abstract}

\section{INTRODUCTION}

Fires are a tremendous hazard to both natural resources and human activities. Every year, more than $4 \mathrm{Mkm}^{2}$ (Chuvieco et al., 2019) of land burn globally, causing significant ecological and economic consequences, and associated climatological and health effects as a result of fire emissions (O'Donnell et al., 2011; Thelen et al., 2013; Van Der Werf et al., 2017). In Chile, there has been a continuous increase in the number of fires occurred in the country since 1975 . The average annual reported burned area was around 100.000 ha with an average fire size of 10 ha. However, the devastating fires that affected the Central region of Chile in 2017 marked a breaking point and possibly signalled a change in the fire regime of the country. More than 500.000 ha were burned, more than 1.000 homes were consumed by the fire and 11 deaths were the tragic result of Chile 2017 fire season.

It is expected that due to climate change Central Chile will experience longer drought periods and higher temperatures, which will result in dryer fuels available for burning favouring longer and more intense fire seasons with larger and more severe forest fires (Rogers et al., 2011). These conditions highlight the importance of the implementation of a system to report the area affected by forest fires accurately and in a timely manner, so the proper forest management decisions could be making efficiently.

In recent decades, remote sensing products have positioned as a valuable resource to monitor Earth dynamics. In particular, burned area estimates generated from satellite data have provided systematic global information for ecological analysis of fire impacts, climate, and carbon cycle models, and fire regime studies, among many others (Beverly et al., 2011; Canadell et al., 2010; Mouillot et al., 2014; Van Der Werf et al., 2017). Burned area mapping from satellite images has been performed using a broad set of methods and sensors, from coarse to very high spatial resolution, such as Advance Very High Resolution Radiometer (AVHRR), SPOT-VEGETATION, MODIS, or MERIS (Alonso-Canas and Chuvieco, 2015; Oliva et al., 2011; Roy et al., 2005; Silva et al., 2005; Tansey et al., 2008; Zhang et al., 2003), Landsat TM, ETM and OLI
(Bastarrika et al., 2011; Hawbaker et al., 2017; Koutsias and Karteris, 2000), Worldview or Ikonos (Dragozi et al., 2014; Wu et al., 2015).

The recent successful launches of Sentinel-2A (2015) and Sentinel-2B (2016) marked the beginning of a new era in the development of remotely sensed products, as the combined detections of both satellites reduced the revisit time to 5 days. In addition, Sentinel-2 Multispectral Imager (MSI) sensor improve upon their predecessors by providing information at 10 and 20 $\mathrm{m}$ and including a wider range of spectral bands (Drusch et al., 2012). The enhanced characteristics of Sentinel-2 MSI make the sensor specially indicated to fill current gaps in knowledge and improve current products. The enhanced spatial resolution of Sentinel-2 allows a more detailed analysis of fire perimeters, as well as a better definition of small fires ( $<25$ ha) which will be most likely missed in coarser resolution products (Roteta et al., 2019).

The design of a burned area algorithm requires considering the vast diversity of ecosystems affected by fires, since the spectral response and the burn severity of the burned areas differ greatly among ecosystems. That is why novel studies have explore the use of machine learning techniques, such as Random Forest (Ramo and Chuvieco, 2017), neural networks (Ba et al., 2019), support vector machines (Dragozi et al., 2014) or genetic programming (Cabral et al., 2018), or the application of objectbased analysis (Dragozi et al., 2014; Shimabukuro et al., 2015). The most extended approaches are based on (i) using active fire detections to guide the sample selection used to compute the burned area statistics introduced in the algorithm (AlonsoCanas and Chuvieco, 2015; Fraser et al., 2000; Giglio et al., 2009; Pu et al., 2007), or (ii) applying the two-phase strategy method which in a first instance identifies the strong burned spectral response and in a second phase delineates the rest of the burned area by applying contextual classifiers (AlonsoCanas and Chuvieco, 2015; Bastarrika et al., 2011; Oliva et al., 2011).

Due to the diverse climatic conditions, Chile has a vast diversity of ecosystems expanding from North to South, which produces an important variety of spectra representing burned areas and

\footnotetext{
* Corresponding author
} 
many other land cover classes. This creates particular conditions for burned area algorithm generalization, making the process very challenging. Due to the complexity in the spectral responses of burned area we selected the Random forest method (Breiman, 2001) to develop an automatic burned area classification algorithm. We use random forest because of its ability to integrate data from different sources, being insensitive to outliers and non-normal distributions, and its efficient computing performance. Random forest has also been used in different areas of forest fire research, particularly for fire regimes characterization (Archibald et al., 2009), fire occurrence prediction (Oliveira et al., 2012), and burned area discrimination (Ramo and Chuvieco, 2017).

In this study we analyse the application of the random forest method for burned area discrimination in Chile. The classification model is applied to the whole Chilean territory. Therefore, we aim to accurately map the area affected by both forest and agricultural fires. We explore the optimization of the classifier calibration and analyse the effects of increasing the variability included in the training sample to obtain the most accurate results.

\section{METHODOLOGY}

\subsection{Study area}

Chile is a South American country located in the south-west of the continent, between the Andes and the Pacific Ocean. It is $350 \mathrm{~km}$ wide from west to east in its widest point, but more than $4000 \mathrm{~km}$ long from north to south. Due to its length, several biomes can be found in this country, from deserts in the north, to Mediterranean and temperate forests in the center and subpolar forests in the south (Olson et al., 2001). Fires are most common in Central Chile, between latitudes $30^{\circ} \mathrm{S}$ and $40^{\circ} \mathrm{S}$ since the Atacama Desert in the north does not contain enough vegetation to be affected by fires, and the forests in the south are too cold and moist to burn. In this study, only areas burned from January to March 2017 were detected and analysed.

\subsection{Sentinel-2 MSI data}

In June 2015, the first of the Sentinel-2 mission satellites was launch. The Sentinel-2A satellite provides data at 10,20 and 60 $\mathrm{m}$ of spatial resolution. This satellite provided a temporal resolution of 10 days, which was reduced to 5 days after the launching of Sentinel-2B satellite on March 2017 established at an complimentary orbit. However, since the period from January to March 2017 was analysed in this study, Sentinel-2B images were not available for most fires yet.

Input data for this BA detection was the Level-1C product, which includes Top-Of-Atmosphere (TOA) reflectances. The Level-2A product with Bottom-Of-Atmosphere (BOA) reflectances is preferable, but in the moment of processing the data for this study L2A products were not uploaded to GEE. The L1C product contains 13 bands ranging from the visible region of the spectrum to the red edge, Near Infrared (NIR) and Short-Wavelength Infrared (SWIR) (Drusch et al., 2012). In this study we work at $20 \mathrm{~m}$ spatial resolution.

\subsection{Google Earth Engine}

Google Earth Engine (GEE, https://earthengine.google.com/) is a cloud-computing platform to process satellite data, developed by Google. The platform includes access to a large database of various satellite imagery datasets and a powerful ability of data processing, which makes it suitable for processing large amounts of data (otherwise too heavy to process) or for implementing and publishing various applications to the public. To operate efficiently with GEE the only requirement is a good internet connexion. The GEE API is available with the JavaScript programming language, a code editor where algorithms are developed and a map to visualize results.

\subsection{Temporal composites}

Burned areas were detected analysing the spectral differences observe on land covers after the fire, so two dates were required: pre-fire and post-fire dates. Only areas burned in the post-fire date that were unburned in the pre-fire date were detected as burned. We decided to compute temporal composites to avoid the low data availability found in South Chile due to the frequent cloud coverage. Therefore, the preand post-fire dates are not images acquired on a single date, but temporal combination of images acquired over several months.

The post-fire composite was generated by minimizing the Normalized Burn Ratio spectral index (NBR) (Key and Benson, 1999) over the images acquired from January $1^{\text {st }}$ to March $31^{\text {st }}$ 2017, covering most of the fire season. This minimization selects burned pixels while dismissing most clouds, cloud shadows and snow. The same minimization was applied over the pre-fire period, corresponding to October-December 2016.

\subsection{Development of the generalized Random Forest model}

2.5.1 Workflow: The BA detection in this study was carried out in three steps: 1) selecting sample dataset from different study areas, 2) training a Generalized Random Forest (GRF) model with these data, and 3) applying the GRF to classify BA for all the Chilean territory. After generating a BA product, we inspected it visually. Based on the classification errors observed, new training sites were to improve the resulting BA product. Three iterations were needed to optimize the final product, thus generating three different versions, each more accurate than the previous.

2.5.2 Training data: In each training site, burned and unburned polygons were defined manually to train a Random Forest model specific of each training site. A two-phase strategy was then applied over the burn probability image obtained for each study area. First identifying seeds with a strong burned signal (using as threshold the minimum among the mean burn probabilities from all training polygons) and then extending the burned areas by applying a less strict threshold (50\% burn probability). This way, we produced reference perimeters for every training site. From the classification of the training sites, we randomly selected the training dataset (burned and unburned samples) used to obtain the GRF.

Ten study areas were used for the first version (v1), located between latitudes $33^{\circ} \mathrm{S}$ and $37^{\circ} \mathrm{S}$ where most of the 2017 fires occurred. We sampled 1000 random points from each category (burned and unburned) and study area, with a total of 20,000 training points for introduced in the GRF-v1 model.

In the second version (v2), we added four new training sites. Two around latitudes 38 and $39^{\circ} \mathrm{S}$, where agricultural fires are most common and where overestimation of BA was observed. Another around latitude $47^{\circ} \mathrm{S}$ to include sample points representing the subpolar biome in the south. The last one located between latitudes $31-32^{\circ} \mathrm{S}$ represented the desert from northern Chile where we observed commission errors. More than 27,000 points were used to train the GRF-v2 model. 

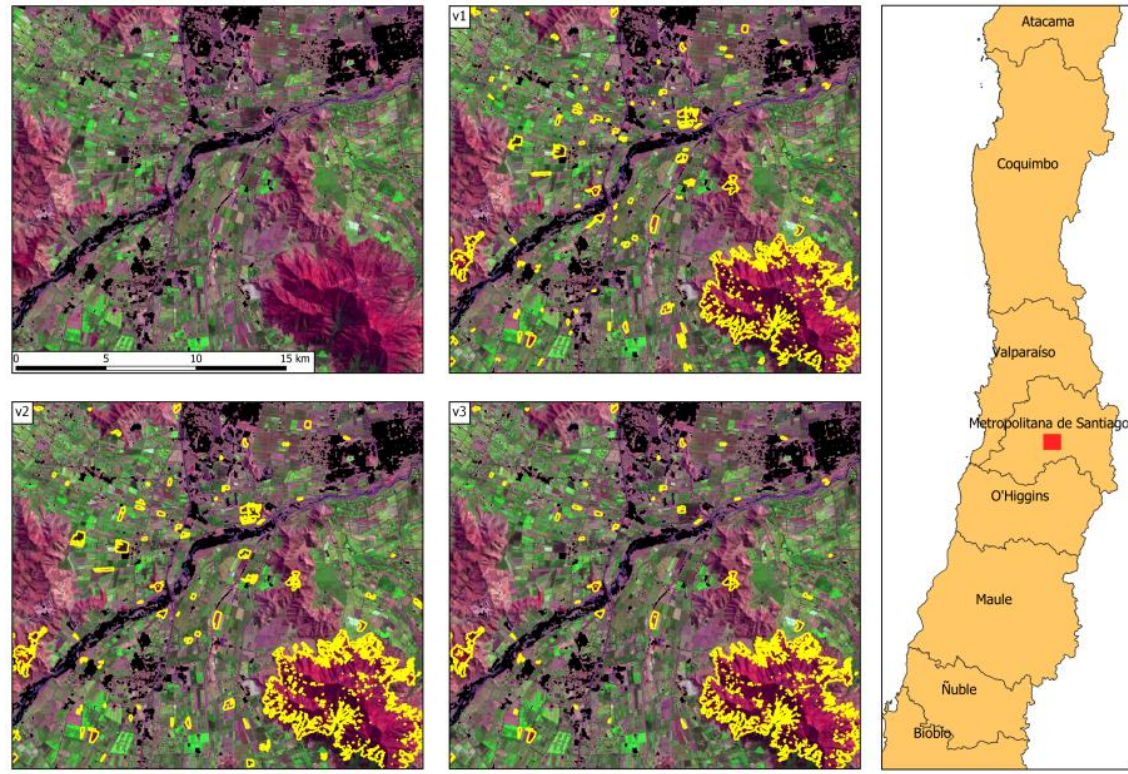

Figure 1. Comparison of different versions of the BA product (yellow line) in a sample area located in the Santiago Metropolitan Region. The background image is the postfire image composite resulting from the combination of the available images from January $1^{\text {st }}$ to March $31^{\text {st }}$.

In the third and final version (v3), eight additional training sites were used. We distributed them throughout Chile (latitudes 30 and $50^{\circ} \mathrm{S}$ ). The training sites were located where we observed a higher presence of errors. Therefore, some of them did not contain any burned area, in which case only training points for the unburned class were sampled. With a total of 22 study areas, the GRF model was trained with almost 40,000 sample points.

2.5.3 The generalized Random Forest model: The Random Forest model (RF) (Breiman, 2001) for each version was created considering 100 decision trees and a minimum of 10 leaves in every branch or node. The model was then trained with the corresponding sampled points and a total of 27 variables:

- 9 original post-fire bands from product L1C: Blue (B2), Green (B3), Red (B4), red edge (B5, B6, B7), NIR (B8A), and Short and Long SWIR (B11, B12).

- 4 post-fire spectral indices: Normalized Difference Vegetation Index (NDVI) (Rouse et al., 1974), Normalized Burn Ratio (NBR) (Key and Benson, 1999), Normalized Burn Ratio 2 (NBR2) (García and Caselles, 1991), and Mid-Infrared Burned Index (MIRBI) (Trigg and Flasse, 2001).

- 13 variables representing the temporal difference between pre- to post-fire composites of the bands and indexes exposed above.

- Relative difference NBR (RdNBR) (Miller and Thode, 2007).

Finally, the GRF classifier was applied on pre- and post-fire composites, resulting in a probability image with values from 0 $\%$ (unburned) to $100 \%$ (burned). To obtain the last BA map, a two-phase strategy was used on this image, resulting in a binary layer of burned and unburned areas; a 100\% threshold was used for identifying seeds, and $50 \%$ to extend burned areas around seeds.

\subsection{Validation strategy}

All three versions of the BA product were visually inspected after their generation, comparing them with pre-fire and postfire temporal composites. These composites were first assigned a SWIR-NIR-Red colour composition, as shown in Figure 1. BA products were also compared with perimeters conceded by the National Forest Corporation (CONAF). By this comparison, we evaluated the goodness of the classification, identified the errors and decided whether more study areas should be included, and where.

\section{RESULTS AND DISCUSSION}

\subsection{Version comparison}

The classification errors observed throughout Chile were mainly due to cloud or relief shadow, and harvested croplands classified as burned. Figure 1 and 2 compare all three BA versions produced for two training sites. Burned areas are detected with very similar shapes in all of them, but small BA corresponding to croplands misclassified as BA are filtered out in later versions. Only the largest agricultural fields remain in GRF-v3, which have a higher burn probability.

In Figure 2, most BA correspond to agricultural fires, but there are many pixel groups belonging to cloud shadows. These shadows are detected as burned in GRF-v1 but are mostly removed in GRF-v3 due to the inclusion of new training sites with this kind of noise. After visual validation of GRF-v3, we decided that the result was the most accurate product that we could produce.

\subsection{Separability analysis}

After a Random Forest model has been trained, it is possible to know the importance that each variable had when creating the decision trees. In, the three most important variables are shown, along with their cumulative importance, for every version of the BA product. According to this Table, the RdNBR is always the most important or second most important variable in these RF models, followed by the temporal differences of NBR and NBR2. Differences of the MIRBI index and post-fire values of the $\mathrm{B} 7$ band appear only once.

According to the cumulative importance, the three most important variables are sufficient to approach $50 \%$ of importance in the decision trees. Nevertheless, the cumulative importance of these variables decreases slightly in later 

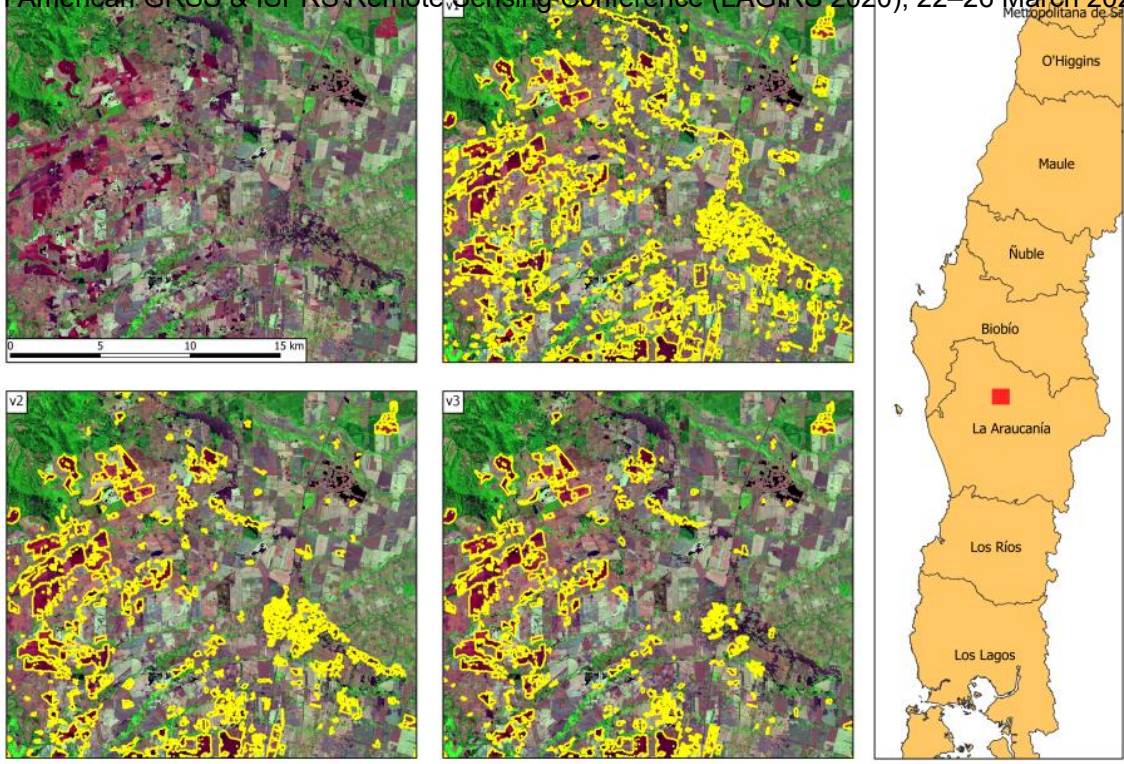

Figure 2. Comparison of different versions of the BA product in a sample area located in the Araucanía Region.

versions, since more study areas were included and sample points became more heterogeneous, indicating that more variables were needed to decide whether a pixel was burned or unburned.

Table 1. The most important variables of the RF model and their cumulative importance in all three versions.

\begin{tabular}{|l|c|c|c|r|}
\hline $\begin{array}{c}\text { BA Product } \\
\text { version }\end{array}$ & $\begin{array}{c}1^{\text {st }} \\
\text { position }\end{array}$ & $\begin{array}{c}2^{\text {nd }} \\
\text { position }\end{array}$ & $\begin{array}{c}3^{\text {rd }} \\
\text { position }\end{array}$ & $\begin{array}{c}\text { Cumulative } \\
\text { importance }\end{array}$ \\
\hline GRF-v1 & RdNBR & dNBR & dNBR2 & $46.6 \%$ \\
\hline GRF-v2 & dNBR & RdNBR & B7 & $43.7 \%$ \\
\hline GRF-v3 & RdNBR & dNBR2 & dMIRBI & $41.5 \%$ \\
\hline
\end{tabular}

\subsection{Comparison with reference data}

The BA product was compared with the official BA perimeters produced by CONAF. A quick view to both perimeters in Figure 3 was enough to see that the BA detected in this study were more accurate than those by CONAF, since the later did not account for the unburned islands inside the BA perimeter. The mismatch between BA perimeters due to inclusion of unburned island has also been reported in previous studies (Ramo and Chuvieco, 2017).

While our BA product works at $20 \mathrm{~m}, \mathrm{CONAF}$ perimeters seem to have a lower spatial resolution, since the border of the polygons are smoother.

We also observed that some pixels without a strong burned signal were classified as unburned by the GRF-v3 BA product. It is difficult to decide which BA delineation is correct in this case based only on the colour composition from Figure 3.
Vegetation under the canopy might be burned, which is difficult to distinguish from satellite imagery if the upper canopy remains unburned and green.

Overall, the CONAF perimeters seem to generally overestimate burned areas when compared to the GRF-v3 BA product. There are also some small BA that are not identified by CONAF.

\subsection{Product assessment}

According to GRF-v3 BA product, around $5,460 \mathrm{~km}^{2}$ were burned in Chile in January, February and March 2017, a considerable increase compared to the average annual 1,000 $\mathrm{km}^{2}$. From this total surface, $20 \%$ corresponds with burned areas larger than $1,000 \mathrm{~km}^{2}$ (Figure 4). In fact, this corresponds to a single burned area located in the Maule Region. $47 \%$ of the burned surface was divided in BA between 10 and 1000 $\mathrm{km}^{2}$, and $67 \%$ of the total burned surface $\left(3,660 \mathrm{~km}^{2}\right)$ was represented in burned patches larger than $10 \mathrm{~km}^{2}$. Only $33 \%$ of the burned surface $\left(1,800 \mathrm{~km}^{2}\right)$ corresponds to BA smaller than $10 \mathrm{~km}^{2}$.

When analysing the burned surfaces by region, we found that most of the BA is in Central Chile (Figure 5), as expected. The Maule Region contains $2240 \mathrm{~km}^{2}$ of burned surface, $41 \%$ of the total. Following by O'Higgins $\left(735 \mathrm{~km}^{2}, 13.4 \%\right)$, Biobío $\left(640 \mathrm{~km}^{2}, 11.7 \%\right)$, Araucanía $\left(550 \mathrm{~km}^{2}, 10 \%\right)$, Nuble $(470$ $\left.\mathrm{km}^{2}, 8.6 \%\right)$ and Santiago Metropolitan Region $\left(320 \mathrm{~km}^{2}, 5.9\right.$ $\%)$. All these 6 regions amount to $91 \%$ of the total burned surface in Chile. In the four northern regions we accounted only $2 \mathrm{~km}^{2}$ of burned surface. Even though there are some small BA areas in these regions, most of the detected BA are commission errors due to relief shadows.
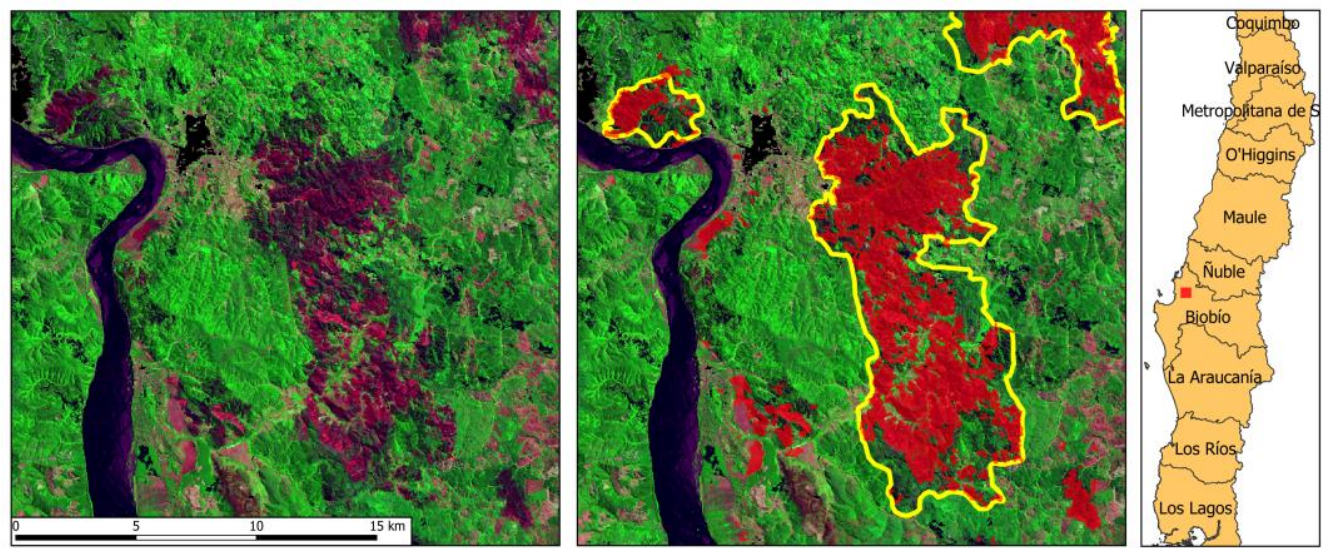

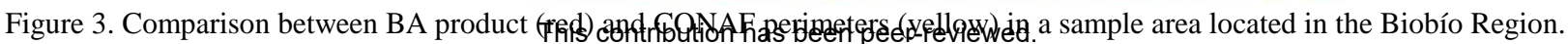
https://doi.org/10.5194/isprs-archives-XLII-3-W12-2020-337-2020 | ๔ Authors 2020. CC BY 4.0 License. 


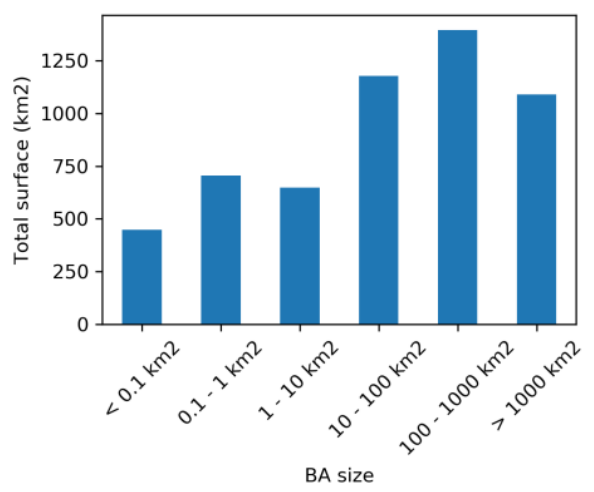

Figure 4. Distribution of burned surface by BA sizes.

\section{CONCLUSIONS}

This study presents the optimized calibration of a generalized random forest model which could be applied to classify burned area in Chile automatically. We showed the importance of the training sample in the classification result and the need to include a diverse set of land covers and burned area conditions to unsure the accuracy of the fil product, supporting previous studies (Colditz, 2015). We produced a BA classification which improved current BA perimeters offered by CONAF, since our product considers unburned patches inside burned areas, detects more small BA areas and includes agricultural fires. In addition, it is implemented in GEE ensuring the operational efficiency of the methodology.

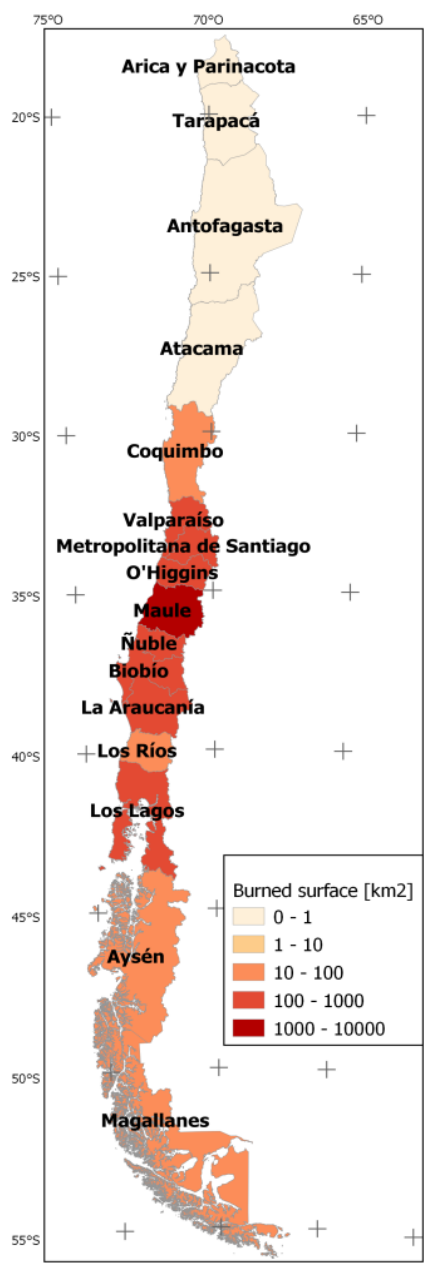

Figure 5. Total burned surface by region.

\section{ACKNOWLEDGEMENTS}

This study was supported by the project FONDECYT Iniciación N11181331 funded by the Chilean Government and the project Fire CCI funded by the European Commission.

\section{REFERENCES}

Alonso-Canas, I., Chuvieco, E., 2015. Global burned area mapping from ENVISAT-MERIS and MODIS active fire data. Remote Sens. Environ. 163, 140-152. https://doi.org/10.1016/j.rse.2015.03.011

Archibald, S., Roy, D.P., WILGEN, V., Brian, W., SCHOLES, R.J., 2009. What limits fire? An examination of drivers of burnt area in Southern Africa. Glob. Chang. Biol. 15, 613-630.

Ba, R., Song, W.G., Li, X.L., Xie, Z.X., Lo, S.M., 2019. Integration of Multiple Spectral Indices and a Neural Network for Burned Area Mapping Based on MODIS Data. Remote Sens. 11 https://doi.org/32610.3390/rs11030326

Bastarrika, A., Chuvieco, E., Martín, M.P., 2011. Mapping burned areas from Landsat TM/ETM+ data with a twophase algorithm: Balancing omission and commission errors. Remote Sens. Environ. 115, 1003-1012. https://doi.org/10.1016/j.rse.2010.12.005

Beverly, J.L., Flannigan, M.D., Stocks, B.J., Bothwell, P., 2011. The association between Northern Hemisphere climate patterns and interannual variability in Canadian wildfire activity. Can. J. For. Res. 41, 2193-2201.

Breiman, L., 2001. Random forests. Mach. Learn. 45, 5-32. https://doi.org/10.1023/A:1010933404324

Cabral, A.I.R., Silva, S., Silva, P.C., Vanneschi, L., Vasconcelos, M.J., 2018. Burned area estimations derived from Landsat ETM plus and OLI data: Comparing Genetic Programming with Maximum Likelihood and Classification and Regression Trees. Isprs J. Photogramm. Remote Sens. 142, 94-105. https://doi.org/10.1016/j.isprsjprs.2018.05.007

Canadell, J.G., Ciais, P., Dhakal, S., Dolman, H., Friedlingstein, P., Gurney, K.R., Held, A., Jackson, R.B., Le Quere, C., Malone, E.L., 2010. Interactions of the carbon cycle, human activity, and the climate system: a research portfolio. Curr. Opin. Environ. Sustain. 2, 301-311.

Chuvieco, E., Mouillot, F., van der Werf, G.R., San Miguel, J., Tanase, M., Koutsias, N., Garcia, M., Yebra, M., Padilla, M., Gitas, I., Heil, A., Hawbaker, T.J., Giglio, L., 2019. Historical background and current developments for mapping burned area from satellite Earth observation. Remote Sens. Environ. 225, 45-64. https://doi.org/10.1016/j.rse.2019.02.013

Colditz, R.R., 2015. An Evaluation of Different Training Sample Allocation Schemes for Discrete and Continuous Land Cover Classification Using Decision Tree-Based Algorithms 9655-9681. https://doi.org/10.3390/rs70809655

Dragozi, E., Gitas, I.Z., Stavrakoudis, D.G., Theocharis, J.B., 2014. Burned area mapping using support vector machines and the FuzCoC feature selection method on VHR IKONOS imagery. Remote Sens. 6, 12005-12036.

Drusch, M., Del Bello, U., Carlier, S., Colin, O., Fernandez, V., Gascon, F., Hoersch, B., Isola, C., Laberinti, P., Martimort, P., Meygret, A., Spoto, F., Sy, O., Marchese, F., Bargellini, P., 2012. Sentinel-2: ESA's Optical HighResolution Mission for GMES Operational Services. Remote Sens. Environ. 120, 25-36. https://doi.org/10.1016/j.rse.2011.11.026

Fraser, R.H., Li, Z., Cihlar, J., 2000. Hotspot and NDVI differencing synergy (HANDS): A new technique for 
burned area mapping over boreal forest. Remote Sens. Environ. 74, 362-376. https://doi.org/10.1016/S00344257(00)00078-X

García, M.J.L., Caselles, V., 1991. Mapping burns and natural reforestation using thematic Mapper data. Geocarto Int. 6, 31-37. https://doi.org/10.1080/10106049109354290

Giglio, L., Loboda, T., Roy, D.P., Quayle, B., Justice, C.O., 2009. An active-fire based burned area mapping algorithm for the MODIS sensor. Remote Sens. Environ. 113, 408-420. https://doi.org/10.1016/j.rse.2008.10.006

Hawbaker, T.J., Vanderhoof, M.K., Beal, Y.-J., Takacs, J.D., Schmidt, G.L., Falgout, J.T., Williams, B., Fairaux, N.M., Caldwell, M.K., Picotte, J.J., Howard, S.M., Stitt, S., Dwyer, J.L., 2017. Mapping burned areas using dense time-series of Landsat data. Remote Sens. Environ. 198, 504-522. https://doi.org/10.1016/j.rse.2017.06.027

Key, C.H., Benson, N., 1999. The Normalized Burn Ratio (NBR): a Landsat TM radiometric measure of burn severity. US Geol. Surv. North. Rocky Mt. Sci. Center.

Koutsias, N., Karteris, M., 2000. Burned area mapping using logistic regression modeling of a single post-fire Landsat5 Thematic Mapper image. Int. J. Remote Sens. 21, $673-$ 687. https://doi.org/10.1080/014311600210506

Miller, J.D., Thode, A.E., 2007. Quantifying burn severity in a heterogeneous landscape with a relative version of the delta Normalized Burn Ratio (dNBR). Remote Sens. Environ. 109, 66-80 https://doi.org/10.1016/j.rse.2006.12.006

Mouillot, F., Schultz, M.G., Yue, C., Cadule, P., Tansey, K., Ciais, P., Chuvieco, E., 2014. Ten years of global burned area products from spaceborne remote sensing-A review: Analysis of user needs and recommendations for future developments. Int. J. Appl. Earth Obs. Geoinf. 26, 6479. https://doi.org/10.1016/j.jag.2013.05.014

O’Donnell, M.J., Fang, J., Mittleman, M.A., Kapral, M.K., Wellenius, G.A., 2011. Fine particulate air pollution (PM2.5) and the risk of acute ischemic stroke. Epidemiology 22, 422-431. https://doi.org/10.1097/EDE.0b013e3182126580

Oliva, P., Martín, P., Chuvieco, E., 2011. Burned area mapping with MERIS post-fire image. Int. J. Remote Sens. 32. https://doi.org/10.1080/01431161.2010.489062

Oliveira, S., Oehler, F., San-Miguel-Ayanz, J., Camia, A., Pereira, J.M.C., 2012. Modeling spatial patterns of fire occurrence in Mediterranean Europe using Multiple Regression and Random Forest. For. Ecol. Manage. 275 , 117-129.

Olson, D.M., Dinerstein, E., Wikramanayake, E.D., Burgess, N.D., Powell, G.V.N., Underwood, E.C., D'amico, J.A., Itoua, I., Strand, H.E., Morrison, J.C., Loucks, C.J., Allnutt, T.F., Ricketts, T.H., Kura, Y., Lamoreux, J.F., Wettengel, W.W., Hedao, P., Kassem, K.R., 2001. Terrestrial Ecoregions of the World: A New Map of Life on Earth. Bioscience 51, 933. https://doi.org/10.1641/00063568(2001)051[0933:TEOTWA]2.0.CO;2

Pu, R., Li, Z., Gong, P., Csiszar, I., Fraser, R., Hao, W.-M., Kondragunta, S., Weng, F., 2007. Development and analysis of a 12-year daily 1-km forest fire dataset across North America from NOAA/AVHRR data. Remote Sens. Environ. 108, 198-208.

Ramo, R., Chuvieco, E., 2017. Developing a Random Forest algorithm for MODIS global burned area classification. Remote Sens. 9. https://doi.org/10.3390/rs9111193

Rogers, B.M., Neilson, R.P., Drapek, R., Lenihan, J.M., Wells, J.R., Bachelet, D., Law, B.E., 2011. Impacts of climate change on fire regimes and carbon stocks of the US Pacific Northwest. J. Geophys. Res. Biogeosciences 116.
Roteta, E., Bastarrika, A., Padilla, M., Storm, T., Chuvieco, E., 2019. Development of a Sentinel-2 burned area algorithm: Generation of a small fire database for subSaharan Africa. Remote Sens. Environ. 222, 1-17. https://doi.org/10.1016/j.rse.2018.12.011

Rouse, J.W., Haas, R.H., Schell, J.A., 1974. Monitoring the vernal advancement and retrogradation (greenwave effect) of natural vegetation. NASA Goddard Sp. Flight Cent. https://doi.org/19740008955

Roy, D.P., Jin, Y., Lewis, P.E., Justice, C.O., 2005. Prototyping a global algorithm for systematic fire-affected area mapping using MODIS time series data. Remote Sens. Environ. $\quad 97$, $137-162$. https://doi.org/10.1016/j.rse.2005.04.007

Shimabukuro, Y.E., Miettinen, J., Beuchle, R., Grecchi, R.C., Simonetti, D., Achard, F., 2015. Estimating Burned Area in Mato Grosso, Brazil, Using an Object-Based Classification Method on a Systematic Sample of Medium Resolution Satellite Images. Ieee J. Sel. Top. Appl. Earth Obs. Remote Sens. 8, 4502-4508. https://doi.org/10.1109/jstars.2015.2464097

Silva, J.M.N., Sá, A.C.L., Pereira, J.M.C., 2005. Comparison of burned area estimates derived from SPOTVEGETATION and Landsat ETM+ data in Africa: Influence of spatial pattern and vegetation type. Remote Sens. Environ. 96, 188-201.

Tansey, K., Grégoire, J., Defourny, P., Leigh, R., Pekel, J., Van Bogaert, E., Bartholomé, E., 2008. A new, global, multi-annual (2000-2007) burnt area product at $1 \mathrm{~km}$ resolution. Geophys. Res. Lett. 35.

Thelen, B., French, N.H., Koziol, B.W., Billmire, M., Owen, R.C., Johnson, J., Ginsberg, M., Loboda, T., Wu, S., 2013. Modeling acute respiratory illness during the 2007 San Diego wildland fires using a coupled emissionstransport system and generalized additive modeling. Environ. Heal. A Glob. Access Sci. Source 12. https://doi.org/10.1186/1476-069X-12-94

Trigg, S., Flasse, S., 2001. An evaluation of different bi-spectral spaces for discriminating burned shrub-savannah. Int. J. Remote Sens. 22, 2641-2647. https://doi.org/10.1080/01431160110053185

Van Der Werf, G.R., Randerson, J.T., Giglio, L., Van Leeuwen, T.T., Chen, Y., Rogers, B.M., Mu, M., Van Marle, M.J.E., Morton, D.C., Collatz, G.J., Yokelson, R.J., Kasibhatla, P.S., 2017. Global fire emissions estimates during 1997-2016. Earth Syst. Sci. Data. https://doi.org/10.5194/essd-9-697-2017

Wu, Z., Middleton, B., Hetzler, R., Vogel, J., Dye, D., 2015. Vegetation burn severity mapping using Landsat- 8 and WorldView-2. Photogramm. Eng. Remote Sens. 81, 143154.

Zhang, Y.H., Wooster, M.J., Tutubalina, O., Perry, G.L.W., 2003. Monthly burned area and forest fire carbon emission estimates for the Russian Federation from SPOT VGT. Remote Sens. Environ. 87, 1-15. https://doi.org/10.1016/S0034-4257(03)00141-X 